\title{
Narrative review of penile distal urethroplasties and suggestions for optimizing outcomes
}

\author{
Matthias D. Hofer ${ }^{1}$, Lauren Folgosa Cooley ${ }^{2}$, Francisco E. Martins ${ }^{3}$ \\ ${ }^{1}$ Urology San Antonio, San Antonio, TX, USA; ${ }^{2}$ Northwestern University Feinberg School of Medicine, Chicago, IL, USA; ${ }^{3}$ University of Lisbon, \\ Lisbon, Portugal \\ Contributions: (I) Conception and design: MD Hofer, FE Martins; (II) Administrative support: MD Hofer, FE Martins; (III) Provision of study \\ materials or patients: MD Hofer, FE Martins; (IV) Collection and assembly of data: All authors; (V) Data analysis and interpretation: All authors; (VI) \\ Manuscript writing: All authors; (VII) Final approval of manuscript: All authors. \\ Correspondence to: Matthias D. Hofer, MD PhD. Urology San Antonio, 7909 Fredericksburg Road, Ste. 110, San Antonio, TX 78229, USA. \\ Email: m-hofer@fsm.northwestern.edu.
}

\begin{abstract}
Distal urethral strictures can be a challenging entity for urologists. Endoscopic maneuvers such as optical internal urethrotomies or dilations are even less successful than in other urethral locations and the repeated trauma will increase the scarring which advocates for a urethroplasty as primary option for patient management. Success rates of distal urethroplasties have been lower than those for other urethral strictures due to the anatomy of the distal urethra with a very thin corpus spongiosum associated with decreased mucosal blood supply. Also, the high prevalence of lichen sclerosus in this population with circumferential scarring is often a complicating factor. However, in the past two decades several surgical techniques have been described and further developed which has led to significant improvement in stricture recurrence rates. Meatoplasties are indicated for strictures limited to the meatus and involve opening of the stenotic meatus with subsequent reconstruction of it to minimize spraying of urine. Often, however, distal urethral strictures involve the fossa navicularis and may even extend further proximally. These strictures can be addressed with dorsal or ventral inlay procedures using buccal mucosa graft. In addition or alternatively, skin flaps can be mobilized to increase the urethral diameter. Lastly, multi-stage urethroplasty with buccal mucosa are a very successful approach yet given the high success rates of above mentioned procedures are usually reserved for revision surgery or most severe distal urethral strictures. In the following report, we are describing a variety of surgical techniques and their indication which should allow the practicing urologist to successfully address all encountered distal urethral strictures.
\end{abstract}

Keywords: Urethroplasty; distal urethral stricture; buccal mucosa graft

Submitted Sep 23, 2020. Accepted for publication Jan 27, 2021.

doi: $10.21037 / \mathrm{tau}-20-1289$

View this article at: http://dx.doi.org/10.21037/tau-20-1289

\section{Introduction}

Distal urethral strictures can be defined as those that involve the meatus and extend into the fossa navicularis. They are a challenging entity for urologists for several reasons. First, these strictures are often associated with lichen sclerosus (1), a chronic inflammatory skin disease which causes extensive urethral scarring. This condition complicates stricture repair as it often requires tissue transfer techniques as insufficient healthy urethral tissue is available. Furthermore, it precludes the use of skin flaps as

$\wedge$ ORCID: 0000-0001-8393-2468. 
they tend to develop lichenoid changes over time rendering the repair to failure (2). Second, the fossa navicularis needs to be reconstructed and loss of its original anatomic shape disturbs physiologic urine flow leading to urine spraying. This anatomic disturbance is often exacerbated by the repair involving the meatus and leads to significant patient dissatisfaction. Lastly, repairs involving the distal urethra have higher failure rates than for repairs at other locations and are reported to be as high as 55\% (3). However, success rates for distal urethroplasties in the past two decades have improved with the advent of buccal mucosa graft techniques and evolution in the understanding of stricture disease and how to approach surgical repair of urethral strictures in general.

In this manuscript we summarize current commonly performed techniques to address distal urethral strictures. While it does not describe every technique that has been reported, we chose to focus on those that have passed the test of time and are the mainstay of our armamentarium to address distal urethral strictures either using each technique by itself or in combination. The goal of this manuscript is to provide an overview that is concise yet comprehensive and that will allow the reader to also address most if not all distal urethral strictures encountered. We present the following article in accordance with the Narrative Review Checklist (available at: http://dx.doi.org/10.21037/tau-20-1289).

\section{Methods}

A PubMed search for English language articles was performed from 1985-2020 and included articles that reported on surgical correction of distal urethral strictures. As there was a wide variation in number of patients, followup, and description of recurrences, we did not apply specific inclusion or exclusion criteria.

\section{Distal urethral strictures}

\section{Etiology}

As mentioned above, lichen sclerosus is a common etiological factor for distal urethral strictures present in $15-42 \%$ of patients $(1,3)$. The extent of lichen sclerosus can vary. It may involve solely the meatus or extending proximally to the fossa navicularis and in some cases the entire anterior urethra. Other common etiologies are iatrogenic including instrumentation (10\% of distal strictures) and catheterization (4\% of distal strictures) (3). Other less common risk factors include condyloma and trauma.

\section{Diagnosis}

The diagnosis of a distal urethral stricture can often be made by physical examination of the penis. Meatal strictures will render a pinpoint meatus as demonstrated in Figure 1A. Palpation of firm scar along the distal urethra may give further clues about the extent of the stricture but lacks accuracy. If the stricture is more proximal then the authors prefer an office cystoscopy to identify the exact location of the stricture. In order to delineate the length of the stricture and also the presence of additional strictures more proximally, we also perform a retrograde urethrogram in the office. While a retrograde urethrogram for evaluation of distal strictures can be particularly challenging as the instrument used to inject contrast may obscure the location or extent of the stricture or fail to identify the stricture the use of an angiocatheter tip usually allows passage of contrast beyond the distal stricture and opacification and evaluation of the remining urethra. If a patient has a suprapubic tube placed, a voiding cysturethrogram is recommended and could also be combined with an antegrade cystoscopy. In general we counsel our patients on a variety of repair options including meatotomy, the use of buccal mucosa grafts and/or skin flaps, as well as the need for multi-stage procedures. We also counsel patients that dilations have a very poor success rate and make further repair more extensive with higher likelihood of failure given the repeated trauma.

\section{Surgical approaches to distal urethroplasties}

\section{Meatotomy and meatoplasty}

Meatotomies can be utilized for strictures limited to the meatus. While the success rate of this procedure is fairly high in children (4) where the etiology is predominantly a narrowed opening of the urethra without underlying scar, this is not the case in adults where the etiology is circumferential scarring. In general, success rates are around $80 \%$ (3) with a ventral incision and then closure of the incision laterally with interrupted sutures. Malone et al. described a variation of a simple meatotomy termed an extended meatal reconstruction (meatoplasty) (5) and reported a $100 \%$ success rate in 19 patients at a mean follow-up of nearly 4' years. In addition, $85 \%$ of patients did not report bothersome spraying of urine, which is a common complaint of patients undergoing meatotomies. While this study included only patients with lichen 

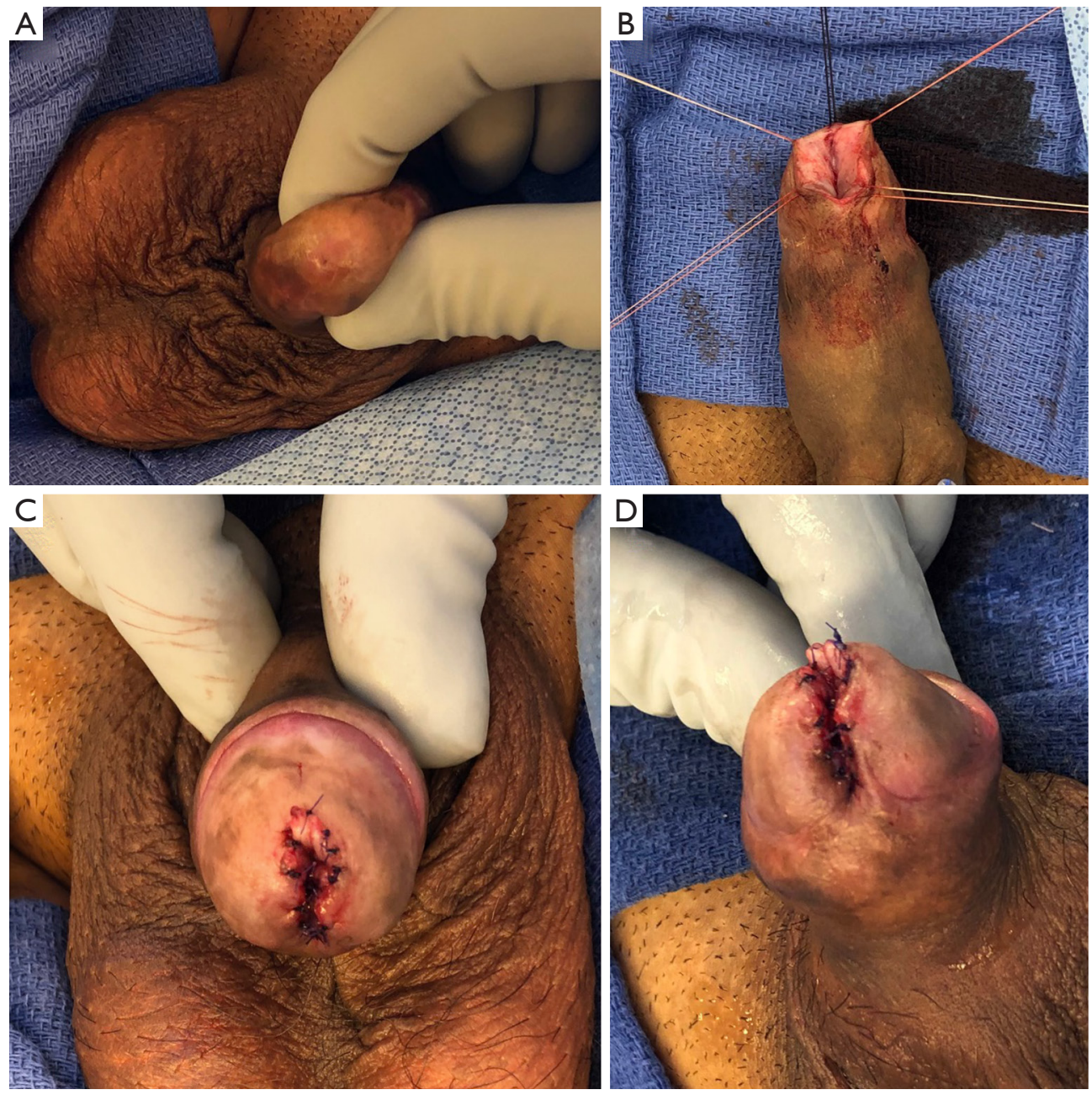

Figure 1 Dorsal inlay urethroplasty. (A) Pinpoint meatal stricture. (B) The ventral aspect of the urethra is incised exposing the stricture; a dorsal midline incision is made. (C) A buccal graft has been placed dorsally and sutured to the graft bed with interrupted 5-0 PDS sutures. (D) View of the ventral distal urethra demonstrating the ventral reconstruction of the neomeatus with interrupted 5-0 PDS sutures.

sclerosus, this technique can be utilized in all patients with distal strictures. The highlight of this technique is (after a small ventral meatotomy is made) to make an incision shaped like an inverted $\mathrm{V}$ dorsally to the meatus with the legs of the inverted $\mathrm{V}$ laterally. The lateral edges are then closed allowing the reconstructed meatus to be smaller which appears to be responsible for the lack of spraying.

It should be emphasized that meatotomies and meatoplasties should only be performed if the stricture is limited to the meatus as otherwise the risk of significant spraying due to a hypospadiac meatus is very high. Unfortunately, most distal urethral strictures extend further proximally severely limiting the indication for pure meatotomies and meatoplasties. Morey et al. reported on an approach of extended meatotomies for strictures that extend proximally towards the fossa navicularis with a success rate of $88 \%$ at 4.5 years follow-up yet this was limited to highly complex presentations or as salvage maneuvers in which the risk of spraying was deliberately taken into account. In our practice, we determine the extent of the stricture intra-operatively by incising the meatus ventrally to the point of healthy urethral tissue and if limited to the meatus will perform a meatoplasty or if it extends into the fossa navicularis we will revert to the techniques described below.

\section{Dorsal inlay}

Dorsal inlay procedures using buccal mucosa graft 


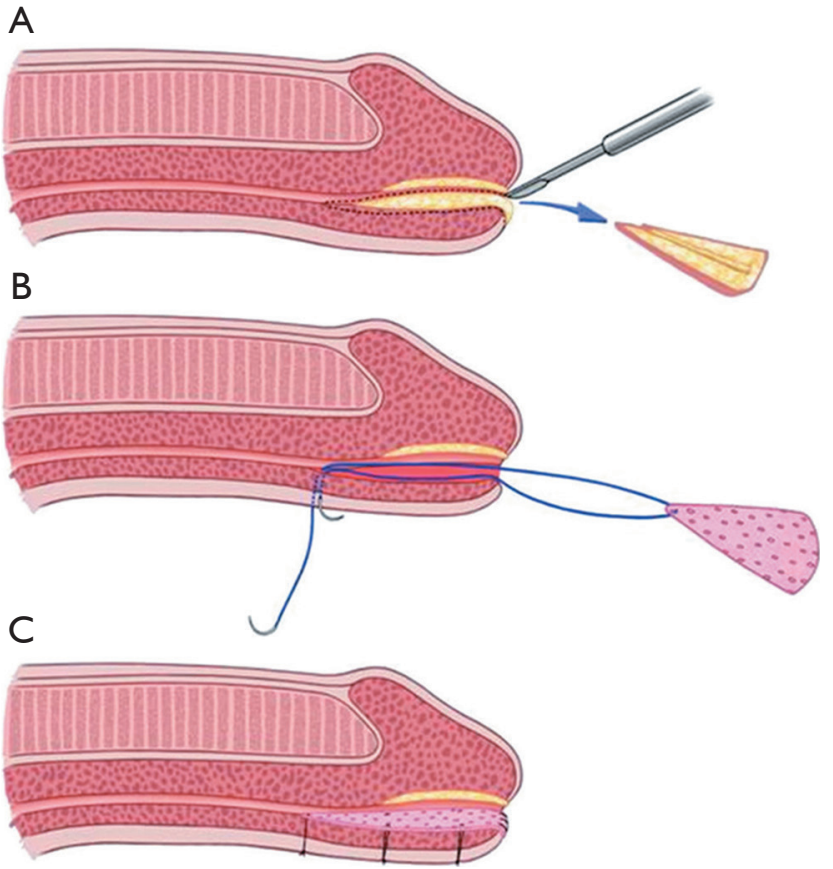

Figure 2 Transurethral placement of a ventral buccal mucosa inlay. (A) A pie slice-shaped area of the stricture is excised ventral by transurethral access. Note that the ventral urethra is not opened. (B) An accordingly-sized buccal mucosa graft is placed into the ventral defect with double-armed sutures at the pie tip that are placed full thickness through the ventral penis to exit on its outer surface. (C) Additional sutures are placed full thickness exiting the penis on its ventral surface where they are tied.

have become a reliable addition to the reconstructive armamentarium for distal urethral strictures $(6,7)$. As mentioned above, unless we are able to determine a stricture location in the fossa navicularis or proximally thereof, we address a distal urethral strictures by a ventral meatal incision extending it proximally until we encounter healthy urethral tissue. We place lateral stay sutures of 4-0 Vicryl in order to keep the urethra spread open (Figure $1 B, C, D$ ). Next, a dorsal incision is made spanning the entire length of the stricture and extending to the tip of the glans. A buccal graft approximately $0.75 \mathrm{~cm}$ wide and as long as the incision is then harvested and placed into the dorsal incision and secured laterally with interrupted 5-0 PDS sutures. Quilting stitches are then applied also with 5-0 PDS. The ventral urethra is then closed with running 5-0 PDS sutures over a 16 French catheter. Next, the ventral glans is closed over the urethra with interrupted 3-0 PDS sutures and the glans edge closed with 5-0 PDS. Lastly, the ventral aspect of the urethra is sutured to the glans edge with interrupted 5-0 PDS in order to complete a circumferential glans reconstruction. This technique has several advantages. First, placement of a buccal inlay (a tissue type that does not develop scarring) improves patency in patients with lichen sclerosus. Second, the dorsal incision minimizes the need for an extended opening ventrally thus reducing the potential of spraying. Third, closure of the ventral urethra and reconstruction of the ventral meatus as last steps enables the surgeon to generate a neomeatus at a desired size. Lastly, this technique is less invasive than skin flap approaches with decreased operative times and shorter catheter duration (10 vs. 21 days). While it is necessary to counsel the patient beforehand about spraying of urine, we have found that patients accepted this consequence given the improved patency rates of $>85 \%$. We have not encountered fistula formation or glans dehiscence yet which we attribute to adequate coverage of the ventral urethral suture line by glans tissue and use of stronger PDS suture for glans reconstruction but acknowledge these possible complications.

\section{Ventral inlay}

Nikolavsky et al. recently described a technique for a transurethral placement of a ventral buccal mucosa inlay (8) which is illustrated in Figure 2. This technique avoids a glans and skin incision ventrally preventing possible complication of fistula formation or glans dehiscence. After placement of traction sutures in triangular fashion at 12, 8 and 4 o'clock, a ventral urethrotomy is performed through the urethra and a wedge-shape of stricture tissue is excised providing a bed for the graft while achieving patency of 24 French or greater. The graft is then harvested and sutured to the ventral graft bed with transcutaneously placed sutures which allows for accurate graft positioning as well as facilitating its placement. In a recent multi-institutional study including 68 patients, $95 \%$ of patients stayed recurrence-free at nearly 1.5 years of follow-up utilizing this technique (9). While technically more challenging than a dorsal inlay, it allows for removal of at least part of the stricture decreasing recurrence rate and also avoiding the possible (albeit theoretical in our experience) risk of fistula formation and glans dehiscence.

\section{Skin flaps}

Skin flaps have long been a mainstay in the repair of distal urethral strictures with transverse island flaps being used predominantly in distal repairs. One main advantage of this 
A

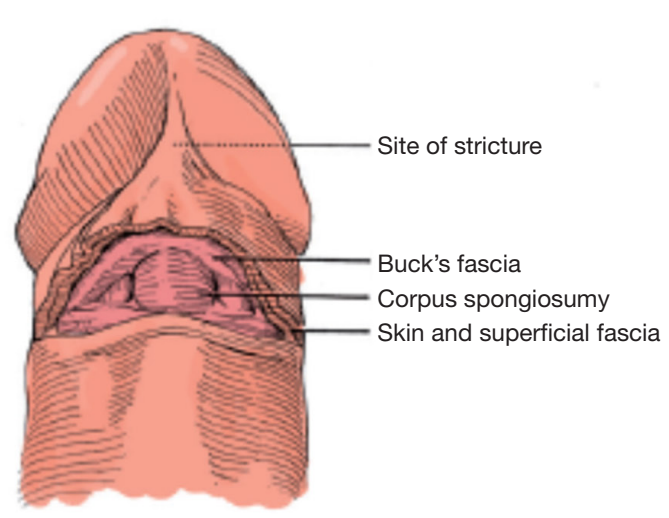

B

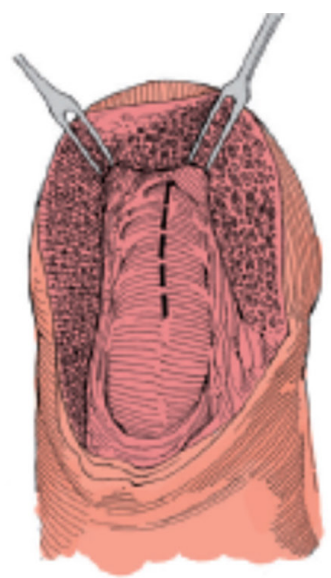

$\mathrm{E}$
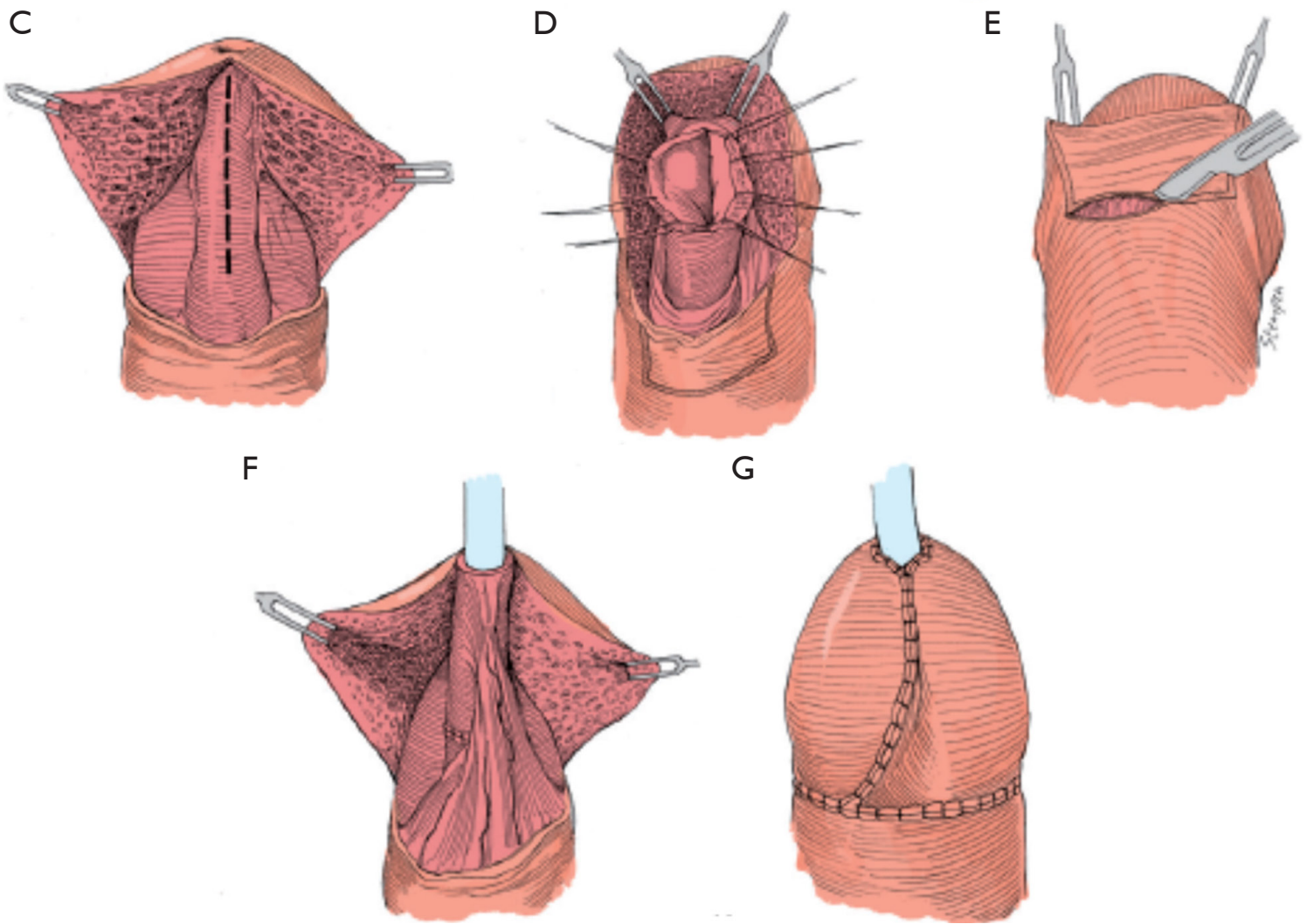

G

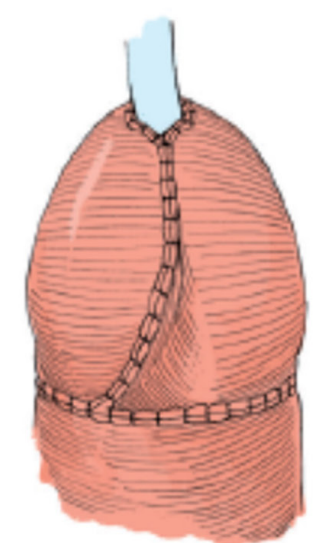

Figure 3 Schematic overview of a transverse island flap (while we prefer a glans cap procedure for illustration purposes we are showing the variation of glans wings). (A) A transverse skin incision has been made over the ventral urethra. (B) The glans is pulled distally to allow access to the distal urethra. (C) The urethra is incised ventrally over the length of the stricture. (D) Stay sutures help to delineate the extend of the stricture. (E) A skin flap is developed on a thick dartos pedicle. (F) The skin flap is sutured to the opened urethra ventrally. (G) The incisions are then closed.

technique is that it is independent of stricture length and can be extended with Orandi flaps if the stricture extends further proximally. This approach was originally described by Jordan in 1987 (10) and again by Armenakas et al. in 1998 with the modification of performing a glans cap approach which allows for preservation of the integrity of the glans without having to incise it (11) (Figure 3). To access the stricture, a vertical incision is made ventrally across the 

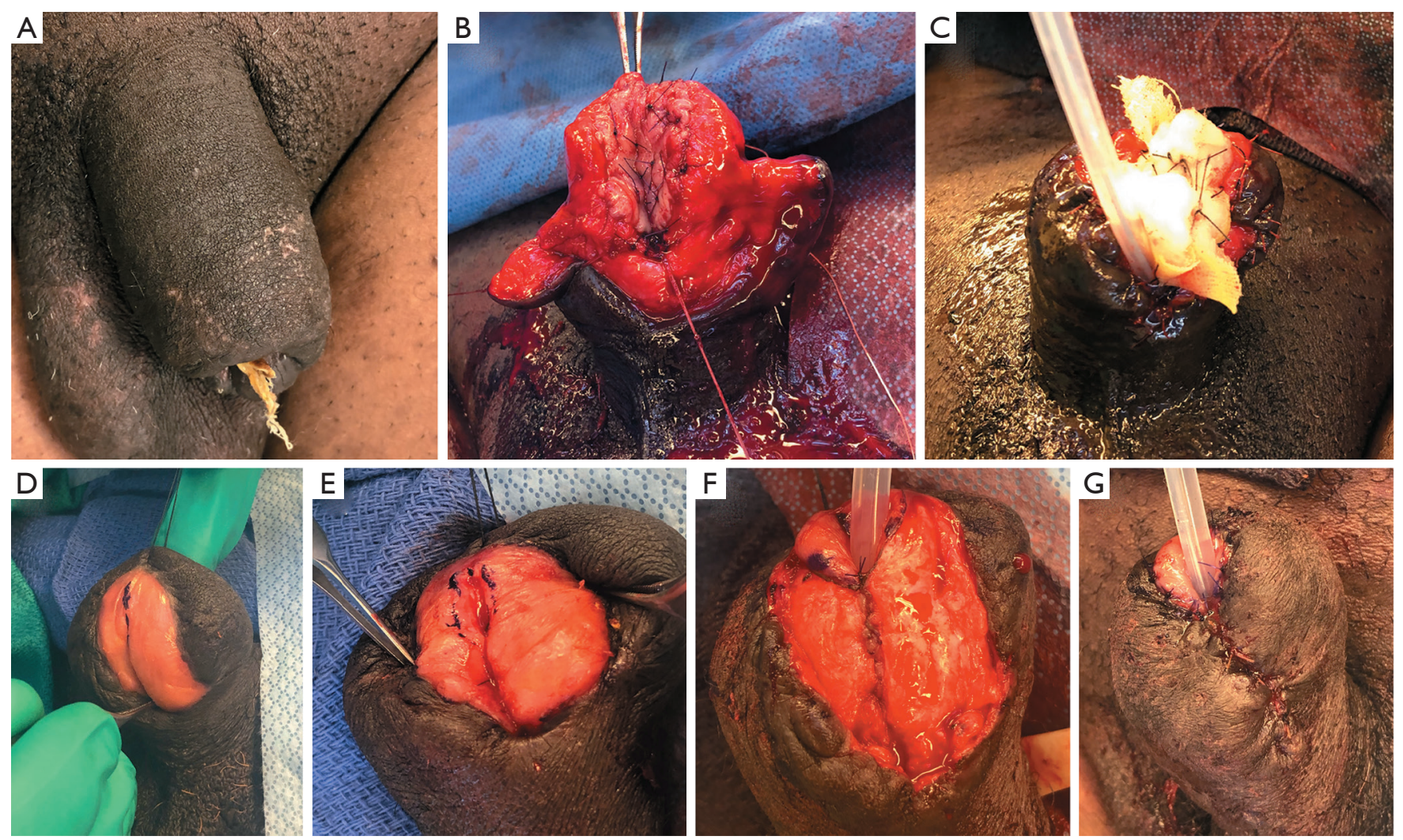

Figure 4 Two-stage repair after loss of part of the glans including distal urethra. (A,B,C): First stage operation: (A) Contraction due to wound healing after removal of a distally extruded and infected penile implant has completely obliterated the distal urethra; a suprapubic tube had been placed during penile prosthesis removal while the tissue was healing. (B) Placement of dorsal buccal graft of at least 3 $\mathrm{cm}$ width. (C) Compression dressing that is left in place for 1 week to improve contact of graft tissue to underlying surface facilitating vascularization of the graft and minimizing seroma and hematoma formation between graft and graft bed. (D,E,F,G) Second stage operation: (D) Appearance of the distal penis with graft in place. (E) The graft is mobilized laterally and a dorsal midline incision is made to provide a groove for the urethra and facilitate tubularization. (F) The urethra is closed ventrally with running 5-0 PDS suture. (G) The skin is closed with interrupted 4-0 Chromic sutures and the ventral aspect of the neomeatus approximated to the penile skin with interrupted 5-0 PDS sutures.

urethra and the dartos tissue is divided until the urethra is reached. This provides enough mobility for the glans to be pulled upward exposing the distal urethra. The urethra is then opened ventrally in between stay sutures for the entire length of the stricture. A suitable skin flap corresponding to the size of the urethral defect is isolated on a pedicle of dartos tissue and sutured inversely to the urethra with running 5-0 PDS sutures so that the external skin forms part of the urethral lumen. A dartos flap can be used to cover this repair but if it has not exceeded the dimension of the glans it is typically not necessary. The skin incision is closed with 4-0 chromic sutures in two layers. A 95\% success rate after 3.5 years of follow-up has been reported (11). As mentioned above, one limitation is this technique cannot be utilized in patients with lichen sclerosus which is present in a large proportion of patients with distal urethral strictures. In our practice, we use transverse island flaps for two main indications: first, if a dorsal inlay provides insufficient diameter for a reconstructed urethra we will combine it with a transverse island graft in order to achieve at least 20 French in size; secondly, it is a useful procedure for patients that have failed prior reconstructive approaches, specifically meatotomies and have developed severe scarring of the dorsal urethra making placement of a graft unreliable. 


\section{Two-stage urethroplasties}

In general, two-stage urethroplasties are rarely necessary but are indicated in patients who have failed multiple distal urethroplasty attempts and having been rendered with insufficient suitable tissue for a successful reconstruction or those with trauma to the distal penis in whom there is variable amounts and quality of distal urethra and/ or glans tissue remaining. Also, two-stage repairs are more commonly necessary in patients with a history of hypospadias that require revision in adulthood although all of the above repair techniques remain indicated (12). It must be emphasized that a third or even a fourth surgery may be necessary due to complications such as fistula development, wound dehiscence, or recurrence which has been reported in $7-59 \%$ of patients (12).

For a two-stage repair (Figure 4), a buccal graft of at least $3 \mathrm{~cm}$ width and of the desired length is placed on the dorsal aspect of the glans. In this example, after an extrusion and infection of a penile implant, part of the glans of the penis including the distal urethra was necrosed and removed. Here, the graft placed on the dorsal aspect of the penis that will become the neourethra. After 8 months to allow sufficient time for vascularization of the graft, the lateral edges were mobilized with careful dissection of the penile tissue away from the graft to preserve its blood supply. Then the graft was tubularized to form the neourethra and closed ventrally with running 5-0 PDS sutures. A dartos flap was developed to cover the suture line and the penile skin closed ventrally with interrupted 5-0 PDS sutures. The catheter was maintained for 4 weeks. The success rate of two-stage repairs is generally very good with the most common complication being fistula formation, which should be minimized by avoiding overlapping suture lines and interposing tissue such as a dartos flap as was done in this case.

\section{Conclusions $(6,7)$}

Distal urethral strictures can be a challenging entity and outcomes have not been as successful as in urethroplasties at other urethral locations. However, a variety of repair options exist, whether utilized alone or in combination, thereof to address distal urethral strictures. Repair options should be chosen which minimize risk of recurrence while achieving the best possible cosmetic result and minimizing spraying during urination afterwards, and thus optimizing patient satisfaction. While not incorporating all reported surgical techniques for distal urethroplasties or the variations herein, the above described techniques provide a collection of commonly performed procedures that have passed the test of time and will enable the urologist to address most if not all distal urethral strictures that are encountered.

\section{Acknowledgments}

Funding: None.

\section{Footnote}

Provenance and Peer Review: This article was commissioned by the editorial office, Translational Andrology and Urology for the series "Controversies and Considerations of Penile Surgery". The article has undergone external peer review.

Reporting Cbecklist: The authors have completed the Narrative Review Checklist. Available at: http://dx.doi. org/10.21037/tau-20-1289

Peer Review File: Available at http://dx.doi.org/10.21037/ tau-20-1289

Conflicts of Interest: The authors have completed the ICMJE uniform disclosure form (available at http://dx.doi. org/10.21037/tau-20-1289). The series "Controversies and Considerations of Penile Surgery" was commissioned by the editorial office without any funding or sponsorship. FM served as the unpaid Guest Editor of the series. $\mathrm{MH}$ serves as an unpaid editorial board member of Translational Andrology and Urology from Mar 2019 to Feb 2021. The authors have no other conflicts of interest to declare.

Ethical Statement: The authors are accountable for all aspects of the work in ensuring that questions related to the accuracy or integrity of any part of the work are appropriately investigated and resolved.

Open Access Statement: This is an Open Access article distributed in accordance with the Creative Commons Attribution-NonCommercial-NoDerivs 4.0 International License (CC BY-NC-ND 4.0), which permits the noncommercial replication and distribution of the article with the strict proviso that no changes or edits are made and the original work is properly cited (including links to both the 
formal publication through the relevant DOI and the license). See: https://creativecommons.org/licenses/by-nc-nd/4.0/.

\section{References}

1. Palminteri E, Berdondini E, Verze P, et al. Contemporary urethral stricture characteristics in the developed world. Urology 2013;81:191-6.

2. Bayne DB, Gaither TW, Awad MA, et al. Guidelines of guidelines: a review of urethral stricture evaluation, management, and follow-up. Transl Androl Urol 2017;6:288-294.

3. Meeks JJ, Barbagli G, Mehdiratta N, et al. Distal urethroplasty for isolated fossa navicularis and meatal strictures. BJU Int 2012;109:616-9.

4. Godley SP, Sturm RM, Durbin-Johnson B, et al. Meatal stenosis: a retrospective analysis of over 4000 patients. J Pediatr Urol 2015;11:38.e1-6.

5. Malone P. A new technique for meatal stenosis in patients with lichen sclerosus. J Urol 2004;172:949-52.

6. Marshall SD, Raup VT, Brandes SB. Brandes: Dorsal inlay buccal mucosal graft (Asopa) urethroplasty for anterior

Cite this article as: Hofer MD, Cooley LF, Martins FE. Narrative review of penile distal urethroplasties and suggestions for optimizing outcomes. Transl Androl Urol 2021;10(6):26092616. doi: 10.21037/tau-20-1289 urethral stricture. Transl Androl Urol 2015;4:10-5.

7. Zumstein V, Dahlem R, Kluth LA, et al. A critical outcome analysis of Asopa single-stage dorsal inlay substitution urethroplasty for penile urethral stricture. World J Urol 2020;38:1283-94.

8. Nikolavsky D, Abouelleil M, Daneshvar M. Transurethral ventral buccal mucosa graft inlay urethroplasty for reconstruction of fossa navicularis and distal urethral strictures: surgical technique and preliminary results. Int Urol Nephrol 2016;48:1823-9.

9. Daneshvar M, Simhan J, Blakely S, et al. Transurethral ventral buccal mucosa graft inlay for treatment of distal urethral strictures: international multi-institutional experience. World J Urol 2020;38:2601-7.

10. Jordan GH. Reconstruction of the fossa navicularis. J Urol 1987;138:102-4.

11. Armenakas NA, Morey AF, McAninch JW. Reconstruction of resistant strictures of the fossa navicularis and meatus. J Urol 1998;160:359-63.

12. Mori RL, Angermeier KW. Angermeier. Staged urethroplasty in the management of complex anterior urethral stricture disease. Transl Androl Urol 2015;4:29-34. 